\title{
Fluoxetine reverses the memory impairment and reduction in proliferation and survival of hippocampal cells caused by methotrexate chemotherapy
}

\author{
Laura Lyons • Maha ElBeltagy • Jariya Umka • \\ Rachel Markwick • Carla Startin • Geoffrey Bennett • \\ Peter Wigmore
}

Received: 23 September 2010 / Accepted: 25 November 2010 /Published online: 22 December 2010

(C) Springer-Verlag 2010

\begin{abstract}
Rationale Adjuvant cancer chemotherapy can cause longlasting, cognitive deficits. It is postulated that these impairments are due to these drugs targeting neural precursors within the adult hippocampus, the loss of which has been associated with memory impairment.

Objectives The present study investigates the effects of the chemotherapy, methotrexate (MTX) on spatial working memory and the proliferation and survival of the neural precursors involved in hippocampal neurogenesis, and the possible neuroprotective properties of the antidepressant fluoxetine.
\end{abstract}

Electronic supplementary material The online version of this article (doi:10.1007/s00213-010-2122-2) contains supplementary material, which is available to authorized users.

L. Lyons $(\bowtie) \cdot$ G. Bennett $\cdot$ P. Wigmore

School of Biomedical Sciences, University of Nottingham,

Queen's Medical Centre,

Nottingham NG7 2UH, UK

e-mail:mbxll@nottingham.ac.uk

M. ElBeltagy

Department of Anatomy, Menoufiya University,

Shibin El-Koom, Egypt

J. Umka

Department of Anatomy, Khon Kaen University,

Khon Kaen, Thailand

R. Markwick

Nursing and Physiotherapy, University of Birmingham,

Birmingham, UK

C. Startin

Behavioural and Brain Science Centre,

University College London,

London, UK
Methods Male Lister hooded rats were administered MTX (75 mg/kg, two i.v. doses a week apart) followed by leucovorin rescue (i.p. $18 \mathrm{~h}$ after MTX at $6 \mathrm{mg} / \mathrm{kg}$ and at $26,42$ and $50 \mathrm{~h}$ at $3 \mathrm{mg} / \mathrm{kg})$ and $/$ or fluoxetine $(10 \mathrm{mg} / \mathrm{kg} /$ day in drinking water for 40 days). Memory was tested using the novel location recognition (NLR) test. Using markers, cell proliferation (Ki67) and survival (bromodeoxyuridine/BrdU), in the dentate gyrus were quantified.

Results MTX-treated rats showed a cognitive deficit in the NLR task compared with the vehicle and fluoxetine-treated groups. Cognitive ability was restored in the group receiving both MTX and fluoxetine. MTX reduced both the number of proliferating cells in the SGZ and their survival. This was prevented by the co-administration of fluoxetine, which alone increased cell numbers.

Conclusions These results demonstrate that MTX induces an impairment in spatial working memory and has a negative long-term effect on hippocampal neurogenesis, which is counteracted by the co-administration of fluoxetine. If translatable to patients, this finding has the potential to prevent the chemotherapy-induced cognitive deficits experienced by many cancer survivors.

Keywords Methotrexate - Fluoxetine - Spatial memory Cognitive impairment $\cdot$ Neurogenesis $\cdot$ Rat

$\begin{array}{ll}\text { Abbreviations } \\ \text { BDNF } & \text { Brain-derived neurotrophic factor } \\ \text { BrdU } & \text { Bromodeoxyuridine } \\ \text { LCV } & \text { Leucovorin/calcium folinate } \\ \text { MTX } & \text { Methotrexate } \\ \text { NLR } & \text { Novel location recognition } \\ \text { PI } & \text { Preference index/indices } \\ \text { SGZ } & \text { Subgranular zone }\end{array}$


SSRI Selective serotonin reuptake inhibitor

THFA Tetrahydrofolate

\section{Introduction}

Many patients who have received adjuvant chemotherapy to treat cancer have experienced cognitive deficits including the reduced ability to form new memories, lack of concentration and general confusion (Taillibert et al. 2007). These symptoms have been reported to persist for several years after completion of the treatment (Ahles et al. 2002; Matsuda et al. 2005), affecting patient quality of life and their ability to work (Ahles and Saykin 2001). The cognitive effects of chemotherapy have been observed in patients who have recovered from a range of cancers (Ahles and Saykin 2001; Kaasa et al. 1988; Taillibert et al. 2007). In studies of breast cancer survivors, most investigations have found a mild to moderate effect on working, visual and verbal memory (Falleti et al. 2005; Jansen et al. 2005; Matsuda et al. 2005; Stewart et al. 2006). Neuroimaging studies of patients showed that chemotherapy treatment affects both grey and white matter volumes (Inagaki et al. 2007; Saykin et al. 2003; Stemmer et al. 1994) with alterations in specific memory-associated areas of the brain, including the hippocampus (Nakano et al. 2002).

Several previous studies have used rodent models to investigate the effect of chemotherapy drugs on different aspects of learning and memory (Fardell et al. 2010; Foley et al. 2008; Gandal et al. 2008; Konat et al. 2008; MacLeod et al. 2007; Mustafa et al. 2008; Seigers et al. 2007; Winocur et al. 2006; Yang et al. 2010), all showing chemotherapy-induced cognitive impairment. Furthermore, some of these studies showed reduced hippocampal neurogenesis as a result of the chemotherapy (ElBeltagy et al. 2010; Seigers et al. 2007; Yang et al. 2010). However, other studies have found that chemotherapy does not affect memory (Foley et al. 2008; MacLeod et al. 2007), or can even cause an improvement (Lee et al. 2006). Comparable to human trials, different drugs and dosing regimens are often used which may explain these anomalies, but the consensus is that cognitive impairment does occur following chemotherapy in both patient and rodents (Hede 2008; Myers 2009).

The effects of cytotoxic drugs on hippocampal neurogenesis is a potential mechanism for the cognitive impairments seen (ElBeltagy et al. 2010; Mustafa et al. 2008; Seigers et al. 2007; Yang et al. 2010). The subgranular zone (SGZ) of the dentate gyrus within the hippocampus is one region of the brain where neurogenesis continues throughout adulthood. The generation of new neurones which are incorporated into the dentate gyrus is thought to have a functional role in both memory consolidation and spatial working memory, both functions of the hippocampal formation (Ehninger and Kempermann 2008; Zhao et al. 2008).

Despite the increasing body of evidence for chemotherapyinduced cognitive impairment, the mechanisms causing this are still not understood and there have been few attempts to counteract it. Fluoxetine is an SSRI antidepressant reported to improve the memory deficits seen in patients with mild cognitive impairment (Mowla et al. 2007), depression (Gallassi et al. 2006; Levkovitz et al. 2002; Vythilingam et al. 2004), post traumatic stress disorder (Vermetten et al. 2003) and traumatic brain injury (Horsfield et al. 2002). These results are supported by rodent investigations showing fluoxetine increases levels of brain-derived neurotrophic factor (BDNF; Alme et al. 2007; Duman and Monteggia 2006), the rate of neurogenesis (Chen et al. 2006; Duman 2004; Marcussen et al. 2008) and the survival of new neurones (Duman et al. 2001; Hitoshi et al. 2007) in the hippocampus. All of these factors are thought to play a role in memory consolidation (Kitabatake et al. 2007; Lledo et al. 2006; Zhao et al. 2008). While fluoxetine may not have any beneficial effects on healthy subjects (Monleon et al. 2007), a recent study found that it can improve cognition after 5fluorouracil chemotherapy in rats (ElBeltagy et al. 2010).

The present study investigates whether fluoxetine alters cognitive deficits induced by methotrexate (MTX) chemotherapy in rats, and examines its effect on neurogenesis in the hippocampus. MTX is an antimetabolite, commonly used to treat several types of cancer including breast cancer (Rousseau et al. 2000) and is often used in adjuvant chemotherapy combinations which have been associated with impaired cognition (Falleti et al. 2005; Matsuda et al. 2005). Used in high doses, it is co-administered with leucovorin (LCV) to reduce its toxicity. MTX is an inhibitor of tetrahydrofolate (THFA) reductase and THFA is necessary for DNA synthesis. LCV is a THFA which doesn't require THFA reductase, replenishing pools depleted by MTX (Genestier et al. 2000; Seigers et al. 2007). The dose and protocol chosen in the present study is within the range of clinical doses (Lobo and Balthasar 2002; Peters et al. 1993), and has been used by Seigers et al. who found them to significantly suppress hippocampal cell proliferation in the adult rat (Seigers et al. 2007). Moreover, the fluoxetine was delivered orally to mimic clinical administration and to prevent the stress of injection. The dose was chosen from previous work in our laboratory which counteracted memory deficits caused by the chemotherapy agent 5-fluorouracil (ElBeltagy et al. 2010). Fluoxetine was given for 40 days before, during and after MTX treatment as it takes at least 21 days in rat to have anxiolytic effects (Conley and Hutson 2007) and increase neurogenesis in the hippocampus (Kodama et al. 2004). Spatial memory was tested 6 days after the end of fluoxetine treatment, as it 
takes 3 days to wash out of the system (Caccia et al. 1990), using the novel location recognition (NLR) test (Dix and Aggleton 1999) and the drug's effects on both survival and proliferation of new-born hippocampal neurones were determined.

\section{Materials and methods}

Animals and treatment

Male Lister hooded rats (150-200 g; Charles River, UK) were randomly allocated to vehicle $(n=12)$, MTX/LCV $(n=$ $12)$, fluoxetine $(n=12)$ or MTX/LCV+fluoxetine $(n=11)$ groups. Animals were housed in cages of four and allowed to habituate for 2 weeks prior to drug administration.

Rats in MTX/LCV groups were administered MTX $(75 \mathrm{mg} / \mathrm{kg}$, two i.v. doses a week apart, at a volume of $0.5 \mathrm{ml} / \mathrm{kg}$; Mayne Pharma Plc, UK) and rats in non-MTX/ LCV groups were given an identical volume of $0.9 \%$ sterile saline (i.v.). LVC (CP Pharmaceuticals, UK; or saline for non-MTX/LCV groups) was administered i.p. $18 \mathrm{~h}$ after each MTX injection at $6 \mathrm{mg} / \mathrm{kg}$ and 26, 42 and $50 \mathrm{~h}$ after at $3 \mathrm{mg} / \mathrm{kg}$ (at a volume of $1 \mathrm{ml} / \mathrm{kg}$ ). BrdU was administered to all groups on the day of their first injection $(250 \mathrm{mg} / \mathrm{kg}$, i.p., at a volume of $5 \mathrm{ml} / \mathrm{kg}$; Sigma Aldrich, UK).

Mean water consumption and animal weight were monitored throughout the experiment. Fluoxetine (Pinewood Healthcare, Ireland, Oral solution) was administered in drinking water at a dose of $10 \mathrm{mg} / \mathrm{kg} / \mathrm{day}$, estimated from the water consumption and calculated on a daily basis. Fluoxetine-treated drinking water was administered to animals in these groups for 40 days, starting a week prior to first MTX injection.

MTX or saline equivalent was administered by i.v. injection to the tail vein in $0.9 \%$ saline under isofluorane anaesthetic. Injection courses began 3 weeks after animal arrival.
Throughout the experiment, rats were maintained with a 12h light/dark cycle $(7.00 / 19.00 \mathrm{~h})$ with ad libitum food and water. Principles of laboratory animal care were in accordance to UK Home Office Guidance regulations and with local ethical committee approval.

\section{Behavioural testing}

\section{Novel location recognition}

The NLR test used here is a spatial variant of a two trial object recognition task adapted from Dix and Aggleton (Dix and Aggleton 1999; Fig. 1). The apparatus consisted of an arena (a semi-transparent Perspex box, dimensions; 49 -cm wide $\times 66-\mathrm{cm}$ long $\times 40-\mathrm{cm}$ high) and pink, weighted water bottles (replicas, $15-\mathrm{cm}$ high, 7-cm diameter). Arenas and water bottles (objects) were cleaned with $20 \%$ ethanol prior to each experiment and between trials to remove olfactory cues. A black square of card was on the wall of the room during trials to provide prominent cues for spatial orientation. Experiments were conducted at an illumination of 80 Lux between 0900 and 1400 hours.

Testing was carried out 6 days after fluoxetine treatment ended. Rats were habituated to the arena for $30 \mathrm{~min}, 24 \mathrm{~h}$ prior to testing (during which EthoVision 4.1 was used to measure the mean velocity of the rats) and for $3 \mathrm{~min}, 5 \mathrm{~min}$ before the familiarisation trial (King et al. 2004). During the 3-min familiarisation trial, rats were placed in the arena to explore two identical objects in separate corners. Rats were returned to their home cage for $15 \mathrm{~min}$ and then returned to the arena for the 3-min choice trial. In this trial, one of the objects remained in the same place and one had been moved to a new location and the rats were again left to explore the two objects. The starting location of objects was randomised. Exploration was defined as the rat directing its nose in the direction of the object less than $1 \mathrm{~cm}$ from the object, and actively exploring it (Dix and Aggleton 1999).

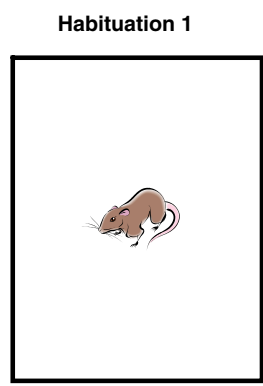

30 mins

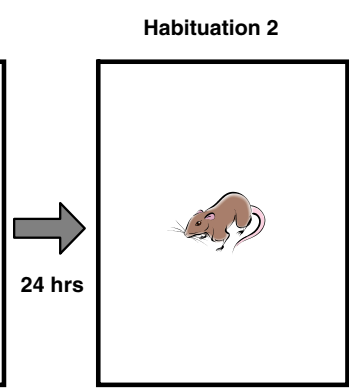

3 mins

Fig. 1 The novel location recognition protocol was carried out over 2 days. Rats were habituated in the arena for $30 \mathrm{~min}$ and for a further $3 \mathrm{~min} 24 \mathrm{~h}$ later. They were then removed for $1 \mathrm{~min}$ whilst two identical objects were placed in two corners of the arena. Rats were

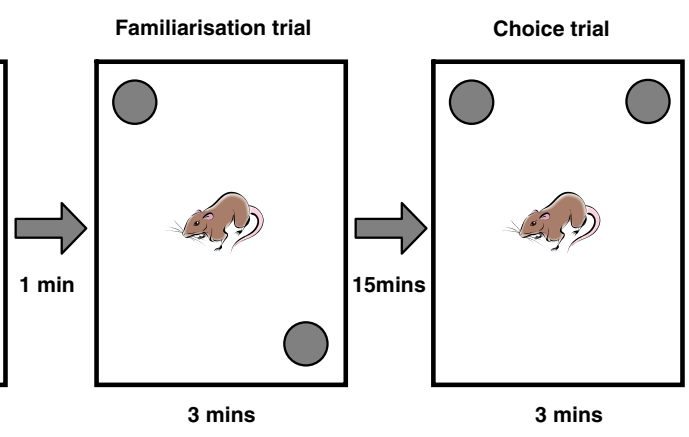

replaced in the arena and allowed to explore the objects for $3 \mathrm{~min}$ (familiarisation trial) then removed again for $15 \mathrm{~min}$. When returned again, one object had been moved to a different corner and rats were again left to explore for $3 \mathrm{~min}$ (choice trial) 
Gnawing or climbing the object was not considered exploration. Exploration times of both objects and trials were recorded blind twice and averaged using a stopwatch from digitised recordings, so no observer was in the room during the trials.

\section{Brain tissue preparation}

The day after behavioural testing was completed rats were put down by rapid stunning and cervical dislocation. Brains were removed, cut sagittally and one half was cryopreserved in $30 \%$ sucrose solution for $3 \mathrm{~h}$ at $4^{\circ} \mathrm{C}$, then embedded in OCT-compound (VWR International Ltd., UK) and snap frozen in liquid nitrogen-cooled isopentane. Brains were stored at $-80^{\circ} \mathrm{C}$ until being coronally sectioned using a Leica CM 100 cryostat (Leica Microsystems, UK) at $20-\mu \mathrm{m}$ thickness at $-20^{\circ} \mathrm{C}$. The sections were thaw mounted onto 3-aminopropylmethoxysaline-coated slides and stored at $-20^{\circ} \mathrm{C}$ until used for immunohistochemistry.

\section{Immunohistochemistry}

For both Ki67 and BrdU staining, a systematic random sampling technique was used (Mayhew and Burton 1988). Every 20th section throughout the entire length of the dentate gyrus was selected, resulting in a total of nine to 11 sections per brain. All immunohistochemistry incubations were carried out at room temperature in a light-proof humidity chamber.

\section{Ki67}

All dilutions and washes (performed three times) were carried out with phosphate-buffered saline (PBS). Sections were fixed using $0.5 \%$ paraformaldehyde (PFA) for $3 \mathrm{~min}$, washed then incubated with monoclonal mouse anti-Ki67 primary antibody (1:300; Vector laboratories, UK) for $1 \mathrm{~h}$, followed by a further wash and 1-h incubation with Alexa 555 donkey anti-mouse (1:300; Invitrogen, UK). Sections then had a final wash, were mounted with (diamidinophenylindole) DAPI $(1.5 \mu \mathrm{g} / \mathrm{ml})$ nuclear marker (Vector laboratories, UK) and coverslipped.

\section{$\operatorname{BrdU}$}

All washes were performed three times with $0.1 \mathrm{M}$ sodium borate adjusted to $\mathrm{pH} 8.5$ (borate buffer) unless otherwise stated. Sections were fixed in 4\% PFA for $3 \mathrm{~min}$, washed, then DNA was denatured by incubation in $2 \mathrm{M}$ hydrochloric acid $(\mathrm{HCl})$ containing $0.3 \%$ triton X-100 (Sigma Aldrich, UK) for $20 \mathrm{~min}$, immediately followed by 10-min incubation with $5 \mathrm{M} \mathrm{HCl}$. Sections were then washed and neutralised for $12 \mathrm{~min}$ in the borate buffer then blocked with 5\% bovine serum albumin (BSA; Sigma Aldrich, UK) in PBS containing $0.15 \%$ triton X-100 for 30 min. After washing, sections were incubated for $16-20 \mathrm{~h}$ with polyclonal sheep anti-BrdU primary antibody $(1: 100$; Abcam, UK) in the blocking solution, followed by washing and incubation with Alexa 488 donkey anti-sheep secondary antibody (1:300; Invitrogen, UK) in PBS. Sections then had a final wash in PBS, mounted with DAPI and coverslipped.

All staining was viewed and quantified at $\times 40$ on a Nikon EFD-3 fluorescence microscope. BrdU- and Ki67positive cells which co-localised with the DAPI nuclear staining within both blades of the dentate gyrus (or within a 3 cell diameter of the inner edge) were counted. By combining cell counts per section for the whole dentate gyrus and multiplying by 20 , an estimate of total co-stained cell numbers was produced (Huang and Herbert 2006). All counting was performed blind.

\section{Statistical analysis}

Statistical analysis and graphs were created using GraphPad Prism 4.0 and significance was regarded as $p<0.05$. Student's paired $t$ tests were used to compare exploration times of animals in the familiarisation and choice trials. Preference indices (PI) were created by expressing time spent exploring the object in the novel location as a percentage of the sum of exploration time of novel and familiar locations in the choice trial, to create a single value to compare between groups (Bruel-Jungerman et al. 2005). PI was compared to $50 \%$ chance using a one-sample $t$ test. One-way ANOVA was used to compare PI, total exploration time and average velocity of the animals and cells counts. Two-way repeated measured ANOVA was run to determine difference in animal weight between treatment groups. When ANOVA was significant Bonferonni post hoc test was performed.

\section{Results}

Methotrexate and fluoxetine reduce weight gain

A two-way repeated measure ANOVA revealed an effect of group $\left(F_{3,43}=4.16, p<0.001\right.$, Supplementary Fig. 1a-b). Rats treated with MTX/LCV, fluoxetine or both in combination gained significantly less weight compared to vehicle-treated controls and this change persisted to the end of the study $(p<0.001)$. This was attributed to disruption of intestinal absorption caused by MTX (Carneiro-Filho et al. 2004) and fluoxetine (Freeman et al. 2006). A significant effect of time and treatment $\times$ time interaction was also confirmed $\left(F_{56,2408}=1793, F_{168,2408}=4.93\right.$, respectively, $p<$ 0.0001 for both). 
Fluoxetine prevents the spatial working memory deficits caused by methotrexate

The NLR test was used to observe the effects of MTX/LCV and fluoxetine on spatial working memory. None of the treatment groups showed a significant difference in the exploration time of the two objects in the familiarisation trial ( $p>0.05$, Fig. 2a), indicating no preference for the location of either object. In the choice trial, Student's paired $t$ tests revealed that the vehicle and fluoxetine-treated groups explored the object in a novel location to a significantly greater extent ( $p<0.01$, Fig. $2 b$ ), suggesting unaffected spatial working memory (Dix and Aggleton 1999). In contrast the MTX/LCV group showed no preference for either the novel or familiar object, showing no significant difference between exploration time for each object $(p>0.05)$. This result indicates that MTX treatment caused a deficit in spatial working memory. Rats administered both MTX/LCV and fluoxetine which showed a significant preference for the object in the novel location $(p<0.05)$ in the choice trial. This group behaved similarly to control or fluoxetine-treated rats and did not show the spatial memory deficit exhibited by the MTX group. Unexpectedly, ANOVA revealed between groups total exploration time for both trials $\left(F_{3,43}=13.29\right.$, $p<0.001)$. It was significantly higher for the fluoxetine group compared to each other group $(p<0.001)$. Further analysis was carried out on exploration times within the choice trial by conversion of raw data into a PI (Bruel-Jungerman et al. 2005; Fig. 2c). PI were created by expressing time spent exploring the object in the novel location as a percentage of the sum of exploration time of novel and familiar locations. This showed the mean PI of the vehicle, fluoxetine and MTX/LCV+fluoxetine groups were significantly different from $50 \%$ chance (one-sample $t$ test, $p>0.05$ ), while the PI of the MTX group was not. Using the PI for comparison between groups using ANOVA however, showed no significant difference between treatment groups $\left(F_{3,43}=1.85, p>0.05\right)$. No significant difference between mean locomotor velocity (recorded during the habituation period; $\left(F_{3,43}=2.70, p>0.05\right.$, Fig. 3) was found between the groups indicating that different groups were not impaired in their activity.
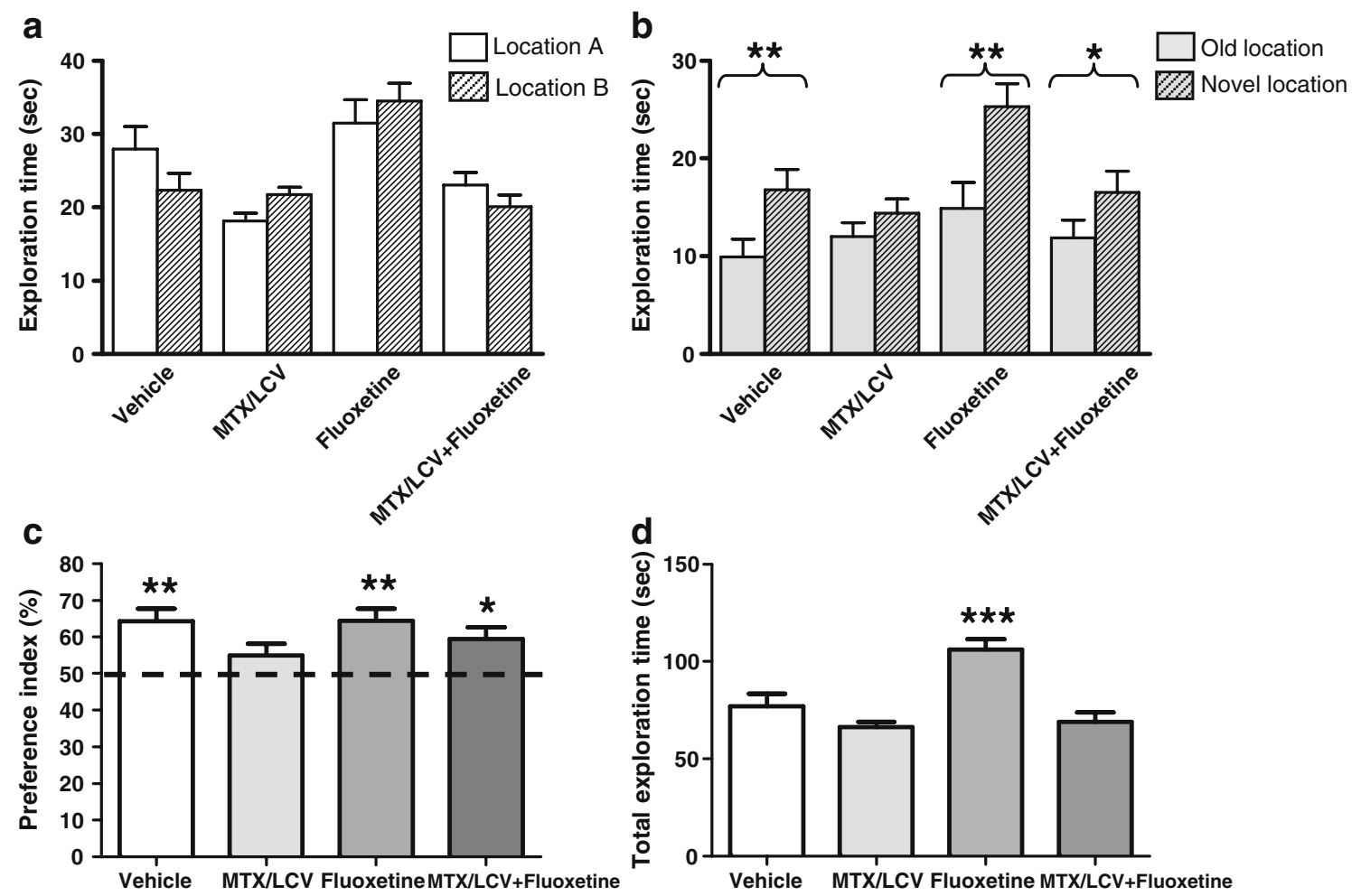

Fig. 2 Mean exploratory times (mean \pm SEM) of the rats for each object in the familiarisation (a) and choice (b) trial of the NLR task. In the familiarisation trial, none of the groups spent a significantly different time exploring either of the two objects $(p>0.05)$. In the choice trial, vehicle-treated, fluoxetine-treated and MTX/LCV administered with fluoxetine-treated rats spent significantly longer exploring the object in the novel location compared with the familiar location (single asterisk, $p<0.05$; double asterisk, $p<0.01$ ), whereas MTX/

LCV failed to discriminate ( $p>0.05$ ). Compared to $50 \%$ chance, mean (mean $\pm \mathrm{SEM})$ preference indices (PI), of the vehicle, fluoxetine and $\mathrm{MTX} / \mathrm{LCV}+$ fluoxetine groups were significantly different (single asterisk, $p<0.05$; double asterisk, $p<0.01$ ), whilst the MTX/LCV group was not (c), however PI was not significantly different between groups $(p>0.05$,). The total exploration time of familiarisation and choice trial combined (d) was significantly higher for the fluoxetine group compared to other groups $(p<0.001)$ 


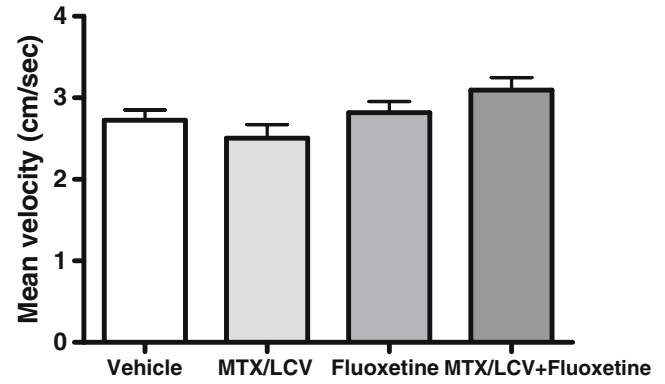

Fig. 3 Mean velocity (mean \pm SEM) of rats $(n=11-12)$ was not significantly different between groups (in all cases $p>0.05$ )

Fluoxetine prevents the reduction in cell proliferation in the SGZ caused by methotrexate

Ki67 was used to quantify the numbers of dividing cells in the SGZ of the dentate gyrus at the end of the experiment, 40 days after the final saline or LCV injection (Fig. 4). A one-way ANOVA showed significant differences between mean Ki67-positive cell counts $\left(F_{3,24}=11.58, p<0.001\right.$, Fig. 4d). Further analysis with a Bonferroni post hoc test revealed that rats treated only with MTX/LCV had a significantly reduced number of Ki67-positive cells, having $48 \%( \pm 3.9 \mathrm{SEM})$ of those found in saline-treated control animals $(p>0.05)$. In contrast, rats treated only with fluoxetine had 37\% ( $\pm 4.5 \mathrm{SEM})$ more Ki67-positive cells compared with the controls, a significant increase $(p>0.05)$. Rats treated with both MTX/LCV and fluoxetine showed no significant difference in Ki67-positive cell numbers from the vehicle-treated controls, indicating that the fluoxetine had prevented the reduction in cell proliferation caused by MTX/LCV.

Fluoxetine reverses reduction in new-born hippocampal cell survival caused by methotrexate

BrdU was administered to rats on the first day of either saline or MTX/LCV injections to label cells undergoing division at the start of treatment. BrdU-positive cells were quantified in the SGZ 48 days later to determine the survival of these cells (Fig. 5). A one-way ANOVA showed significant differences between mean Ki67-positive cell counts $\left(F_{3,20}=24.34, p<0.001\right.$, Fig. 5 d $)$. Bonferroni post hoc test revealed that MTX/LCV treatment significantly reduced the number of BrdU-positive cells $(p<0.001)$ by $66 \%$ ( $\pm 6.4 \mathrm{SEM})$ compared to vehicle-treated controls indicating that the chemotherapy, as well as reducing cell proliferation was reducing the survival of cells dividing at the start of treatment. Treatment with fluoxetine on its own significantly increased BrdU-positive cell numbers by $44 \%$ $( \pm 4.8 \mathrm{SEM} ; p<0.05)$. Animals co-treated with MTX/LCV
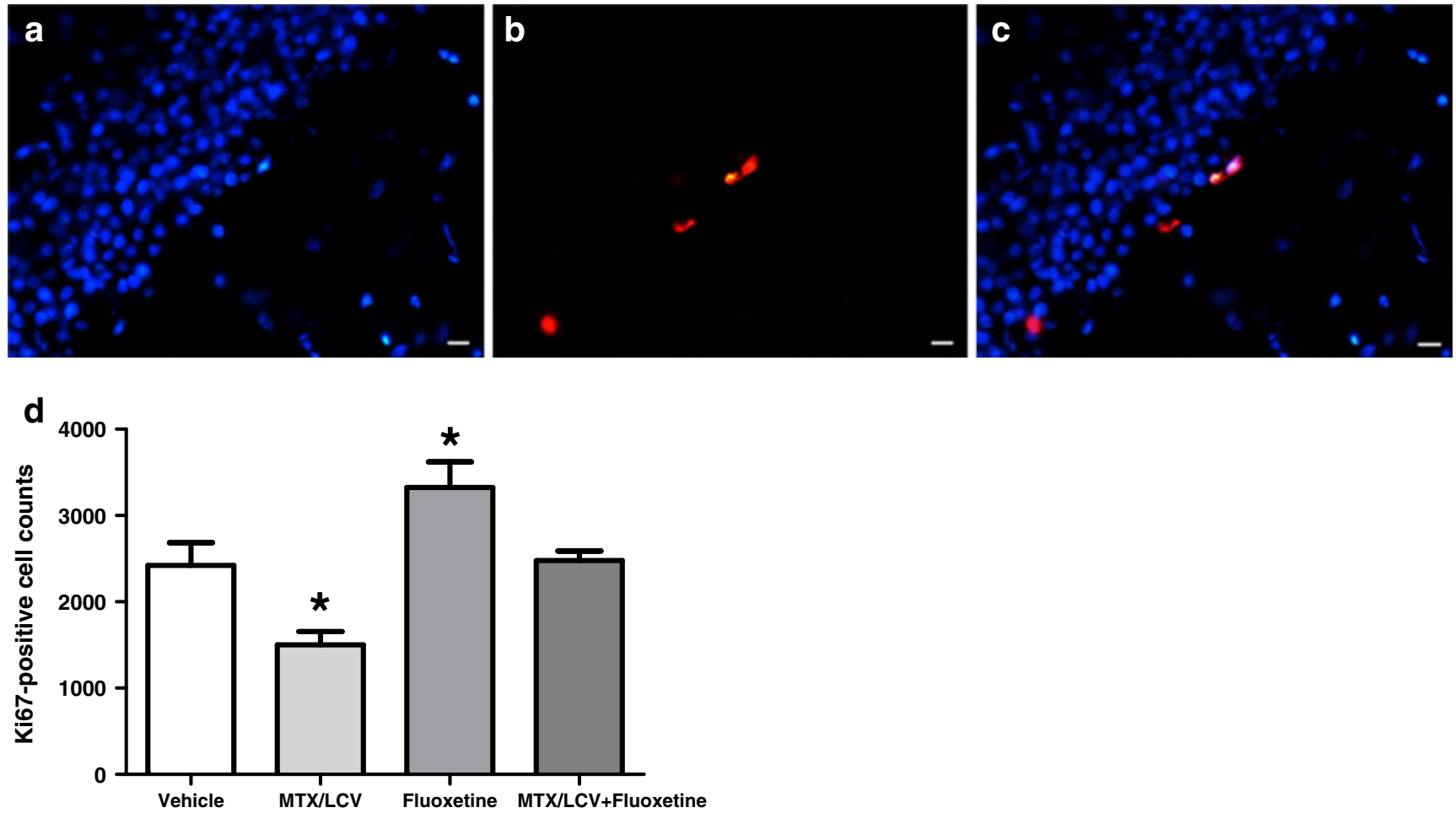

Fig. 4 Photos showing positive immunostaining for proliferating cell marker Ki67 (red; b), nuclear stain DAPI (blue; a) and photos merged (c). Mean Ki67-positive cells counts $(\mathbf{d} ; n=7)$ of the MTX/LCV-

treated group were significantly lower and fluoxetine-treated groups significantly higher compared to the vehicle-treated group (single asterisk, $p<0.05)$. Bar scales indicate $20 \mu \mathrm{m}$ 

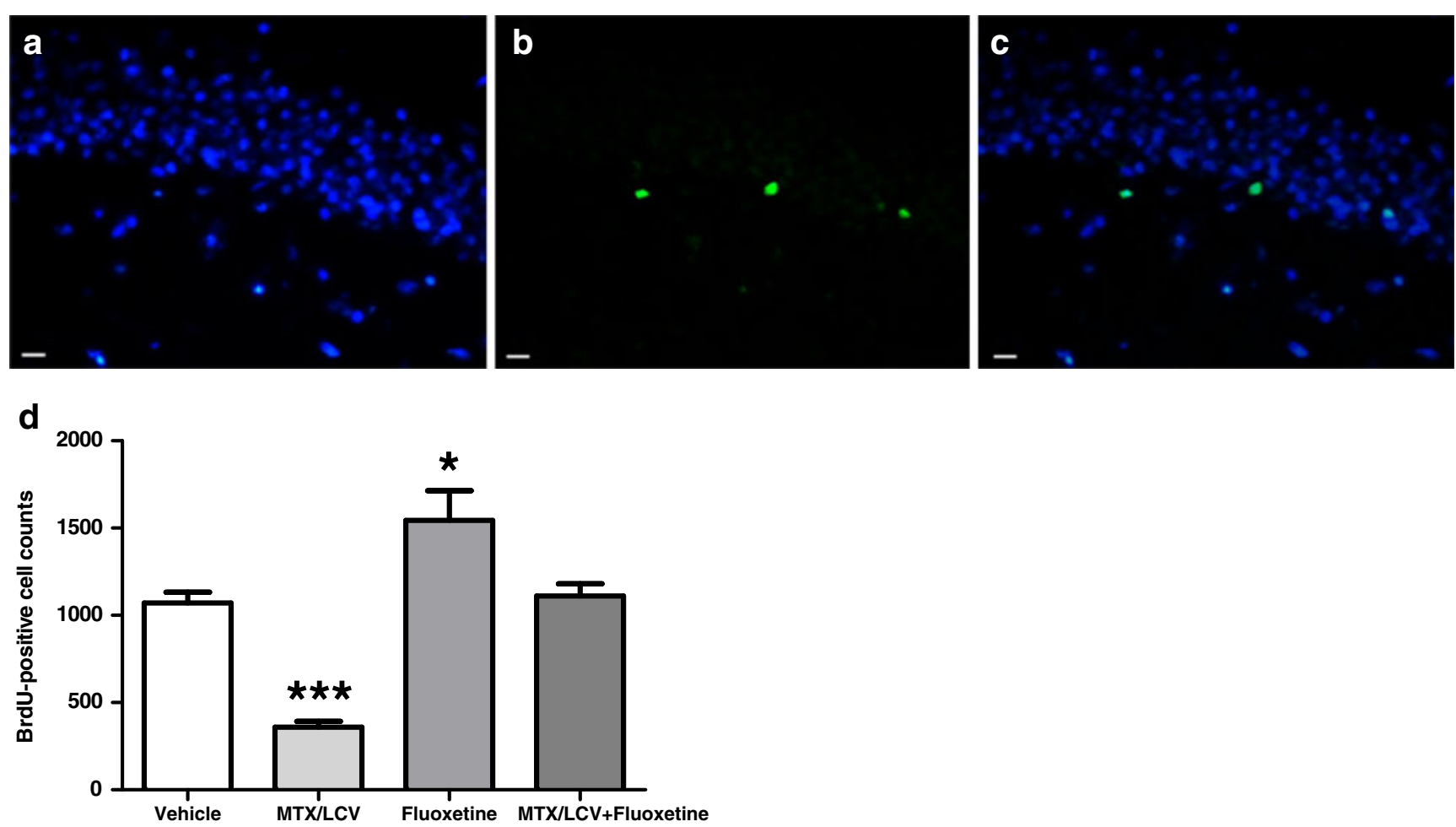

Fig. 5 Immunostaining for BrdU (green; b) encorporated into DNA 48 days prior to rats death, nuclear stainer DAPI (blue; a) and photos merged (c). Mean BrdU-positive cells counts $(\mathbf{d} ; n=6)$ of the MTX/ LCV-treated group were significantly lower and fluoxetine-treated

groups significantly higher compared to the vehicle-treated group (single asterisk, $p<0.05$; triple asterisk $p<0.001$ ). Bar scales indicate $20 \mu \mathrm{m}$

and fluoxetine showed no significant difference in the BrdU-positive cell numbers from vehicle-treated control animals $(p>0.05)$. These results suggest that fluoxetine can protect newly dividing precursors in the dentate gyrus from MTX-induced loss.

\section{Discussion}

The present study aimed to determine, firstly, the long-term effects of MTX chemotherapy on spatial working memory and its effects on cell proliferation and survival in the dentate gyrus of the adult hippocampus. Secondly, we wished to see whether the SSRI antidepressant, fluoxetine, could counteract the behavioural and cellular effects of MTX in a rodent model. The NLR task was chosen to test spatial working memory, firstly, as it is based upon rats' spontaneous preference towards novelty as opposed to positive and negative reinforcements which could confound results. Secondly, it is hippocampal dependent (Mumby et al. 2002) and relies on an intact dentate gyrus rather than other hippocampal subregions to be successfully performed (Lee et al. 2005). The SGZ of the dentate gyrus is one of the brain regions where the formation of new neurons continues throughout life (Ehninger and Kempermann 2008). Newly formed

dentate gyrus neurons have been shown to be preferentially used in spatial learning tasks (Kee et al. 2007) and reductions in dentate gyrus neurogenesis cause deficits in the ability of animals to perform these tasks (Imayoshi et al. 2008). Over $80 \%$ of dividing cells in the SGZ are destined to become dentate gyrus neurones (Snyder et al. 2009). It has been suggested that chemotherapy may reduce hippocampal neurogenesis and cause deficits in the cognitive domains dependent upon this process (Dietrich et al. 2006; ElBeltagy et al. 2010; Han et al. 2008; Mustafa et al. 2008; Seigers et al. 2009). It has previously been assumed that systemic chemotherapy could not cross the blood brain barrier and so would have little effect on the brain. It has now been shown that many chemotherapy agents, including MTX when administered in high doses, can access the brain in significant concentrations (Lassman et al. 2006).

In the present study, animals receiving a 2-week course of MTX/LCV treatment were unable to recognise an object in a novel location from an object in an old location in the NLR behavioural test, 5 weeks after treatment had ended. However animals treated with both MTX/LCV and fluoxetine were able to distinguish the objects. This indicates that MTX causes a decline in spatial working memory compared to vehicle-treated controls or fluoxetine alone, which is counteracted by the co-administration of fluox- 
etine. PI were formed from raw exploration data in the choice trial to produce a single value for comparison between groups. Although the PI of each group other than MTX-treated animals significantly differed from chance, no difference was found between groups, indicating that the memory deficit seen is subtle. The data supports previous reports that chemotherapy can cause spatial memory deficits in both patients (Ahles and Saykin 2002; Matsuda et al. 2005) and animals (ElBeltagy et al. 2010; Gandal et al. 2008; Mustafa et al. 2008; Yang et al. 2010). In particular, high doses of MTX have been shown to produce spatial memory deficits in rats as measured in the Morris water maze, novel object recognition and an instrumental go/no-go tasks (Fardell et al. 2010; Seigers et al. 2007; Seigers et al. 2009). Furthermore, Fardell et al. (2010) demonstrated that these effects were both short and long term, remaining 8 months after treatment, suggesting that MTX has a lasting effect on the stem niche. The present work is consistent with these findings and in addition shows that lower doses are able to produce significant impairments in the NLR test 5 weeks after termination of the treatment. These results are comparable to clinical observations of breast cancer sufferers showing memory deficits after chemotherapy (Matsuda et al. 2005). Most patient studies which have detected cognitive effects of chemotherapy have looked at breast cancer survivors who have received a combination of chemotherapy agents including MTX (Brezden et al. 2000; Wieneke and Dienst 1995). LCV, used here as a recovery drug for the toxic effects of MTX, has been shown to have subtle cognitive benefits in aged rats with a folate deficiency in the hippocampaldependant T-maze task, but not in psychomotor and motor activity and Morris water maze spatial learning tasks. However LCV is thought not to have a cognitive effect on rats with sufficient folate (Lalonde et al. 1993) and Seigers et al. (2009) found it had no effect on neurogenesis when used alone. This allows us to attribute the deficits in memory and neurogenesis seen in the present study to the MTX chemotherapy. Moreover, it is possible that LCV had a positive cognitive effect when co-administered with the MTX, and without it, the memory deficits seen in MTXtreated animals may have been greater.

As spatial learning is thought to depend on both the production and the survival of new-born neurones in the dentate gyrus (Dupret et al. 2007), the effect of MTX on both were investigated. In the present study, MTX/LCV reduced the number of dividing cells in the SGZ of the dentate gyrus, 40 days after the final injection compared to the control group. Survival of cells dividing at the time of the first MTX/LCV injection was also severely reduced. These results suggest that MTX is reducing neurogenesis and provide a mechanism for the cognitive effects produced by this chemotherapy drug.
Fluoxetine is known to improve memory in patients with impaired cognition (Gallassi et al. 2006; Levkovitz et al. 2002; Mowla et al. 2007) and to increase the number of neurons produced during adult neurogenesis in the rodent hippocampus (Kodama et al. 2004; Marcussen et al. 2008). For these reasons, co-administration of fluoxetine with MTX was tested to see if it could prevent the changes produced by chemotherapy. The results show that both the behavioural and cellular deficits were prevented when fluoxetine was given for 40 days. Fluoxetine alone had no effect on PI, or average velocity, but increased total exploration time of animals. We have previously shown that fluoxetine can prevent the cognitive deficits produced by 5-fluoruracil (ElBeltagy et al. 2010) while the present study is the first to demonstrate a reversal of the cognitive deficit induced by MTX suggesting that fluoxetine may be able to prevent the cognitive deficits induced by a range of chemotherapy drugs. The mechanism by which fluoxetine is having these effects is unclear. Fluoxetine may have little effect on cognition or neurogenesis in healthy animals (Huang et al. 2008; Monleon et al. 2007), but has been shown to be neuroprotective after injury (Chiou et al. 2006; Jin et al. 2009) and to up-regulate hippocampal neurogenesis when it is reduced (Duman 2004; Duman et al. 2001; Feldmann et al. 2007). Interestingly, unlike the results shown in the present study, we previously found that fluoxetine did not increase proliferation of cells within the dentate gyrus when administered without chemotherapy (ElBeltagy et al. 2010). This could be attributed to the increased length of time animals received the antidepressant, from 21 days in the previous study to 40 days in the present, highlighting the importance of the period of time for which fluoxetine is administered. In addition, fluoxetine has been reported to increase levels of BDNF (Alme et al. 2007; Duman and Monteggia 2006), a neurotrophic factor which regulates neurogenesis (Alme et al. 2007; Duman et al. 2001). Further investigations to quantify levels of BDNF within the hippocampus may help to understand the pathways by which fluoxetine acts in these situations.

If the effects of the fluoxetine demonstrated in the present study can be translated to patients, it could provide a relatively simple means to alleviate the cognitive effects experienced by some cancer survivors. Further work is needed in both animals and humans to determine the effects of different chemotherapy agents and to examine the impact of other antidepressants. As it has been shown that MTX still affects cell proliferation in the hippocampus after treatment has terminated, experiments investigating the time course of when it would be beneficial to administer antidepressants could generate some interesting results.

In conclusion, this study reveals MTX chemotherapy causes cognitive impairments and a reduction in both the 
proliferation and survival of neural precursors in the hippocampus. Furthermore, these impairments were reversed by the co-administration of the SSRI antidepressant, fluoxetine, suggesting it to have a neuroprotective effect. This finding not only has potential to improve the quality of life for cancer survivors, but provides further information on chemotherapy-induced cognitive deficits and methods to counteract it.

Acknowledgements The authors would like to thank Cancer Research UK for funding this project.

\section{References}

Ahles TA, Saykin A (2001) Cognitive effects of standard-dose chemotherapy in patients with cancer. Cancer Investig 19:812820

Ahles TA, Saykin AJ (2002) Breast cancer chemotherapy-related cognitive dysfunction. Clin Breast Cancer 3(Suppl 3):S84-S90

Ahles TA, Saykin AJ, Furstenberg CT, Cole B, Mott LA, Skalla K, Whedon MB, Bivens S, Mitchell T, Greenberg ER, Silberfarb PM (2002) Neuropsychologic impact of standard-dose systemic chemotherapy in long-term survivors of breast cancer and lymphoma. J Clin Oncol 20:485-493

Alme M, Wibrand K, Dagestad G, CR B (2007) Chronic fluoxetine treatment induces brain region-specific upregulation of genes associated with BDNF-induced long-term potentiation. Neural Plast. doi:10.1155/2007/26496

Brezden CB, Phillips KA, Abdolell M, Bunston T, Tannock IF (2000) Cognitive function in breast cancer patients receiving adjuvant chemotherapy. J Clin Oncol 18:2695-2701

Bruel-Jungerman E, Laroche S, Rampon C (2005) New neurons in the dentate gyrus are involved in the expression of enhanced long-term memory following environmental enrichment. Eur J Neurosci 21:513-521

Caccia S, Cappi M, Fracasso C, Garattini S (1990) Influence of dose and route of administration on the kinetics of fluoxetine and its metabolite norfluoxetine in the rat. Psychopharmacol Berl 100:509-514

Carneiro-Filho BA, Lima IPF, Araujo DH, Cavalcante MC, Carvalho GHP, Brito GAC, Lima V, Monteiro SMN, Santos FN, Ribeiro RA, Lima AAM (2004) Intestinal barrier function and secretion in methotrexate-induced rat intestinal mucositis. Dig Dis Sci 49:65-72

Chen H, Pandey GN, Dwivedi Y (2006) Hippocampal cell proliferation regulation by repeated stress and antidepressants. NeuroReport 17:863-867

Chiou SH, Chen SJ, Peng CH, Chang YL, Ku HH, Hsu WM, Ho LL, Lee CH (2006) Fluoxetine up-regulates expression of cellular FLICE-inhibitory protein and inhibits LPS-induced apoptosis in hippocampus-derived neural stem cell. Biochem Biophys Res Commun 343:391-400

Conley RK, Hutson PH (2007) Effects of acute and chronic treatment with fluoxetine on stress-induced hyperthermia in telemetered rats and mice. Eur J Pharmacol 564:138-145

Dietrich J, Han R, Yang Y, Mayer-Proschel M, Noble M (2006) CNS progenitor cells and oligodendrocytes are targets of chemotherapeutic agents in vitro and in vivo. J Biol 5:22

Dix SL, Aggleton JP (1999) Extending the spontaneous preference test of recognition: evidence of object-location and object-context recognition. Behav Brain Res 99:191-200
Duman RS (2004) Depression: a case of neuronal life and death? Biol Psychiatry 56:140-145

Duman RS, Monteggia LM (2006) A neurotrophic model for stressrelated mood disorders. Biol Psychiatry 59:1116-1127

Duman RS, Malberg J, Nakagawa S (2001) Regulation of adult neurogenesis by psychotropic drugs and stress. J Pharmacol Exp Ther 299:401-407

Dupret D, Fabre A, Döbrössy M, Panatier A, Rodríguez J, Lamarque S, Lemaire V, Oliet S, Piazza P, Abrous D (2007) Spatial learning depends on both the addition and removal of new hippocampal neurons. PLoS Biol 5:e214

Ehninger D, Kempermann G (2008) Neurogenesis in the adult hippocampus. Cell Tissue Res 331:243-250

ElBeltagy M, Mustafa S, Umka J, Lyons L, Salman A, Chur-yoe GT, Bhalla N, Bennett G, Wigmore PM (2010) Fluoxetine improves the memory deficits caused by the chemotherapy agent 5fluorouracil. Behav Brain Res 208:112-117

Falleti MG, Sanfilippo A, Maruff P, Weih L, Phillips KA (2005) The nature and severity of cognitive impairment associated with adjuvant chemotherapy in women with breast cancer: a metaanalysis of the current literature. Brain Cogn 59:60-70

Fardell JE, Vardy J, Logge W, Johnston I (2010) Single high dose treatment with methotrexate causes long-lasting cognitive dysfunction in laboratory rodents. Pharmacol Biochem Behav 97:333-339

Feldmann JRE, Sawa A, Seidler GH (2007) Causality of stem cell based neurogenesis and depression - to be or not to be, is that the question? J Psychiatr Res 41:713-723

Foley J, Raffa R, Walker E (2008) Effects of chemotherapeutic agents 5 -fluorouracil and methotrexate alone and combined in a mouse model of learning and memory. Psychopharmacol Berl 208:112117

Freeman SL, Glatzle J, Robin CS, Valdellon M, Sternini C, Sharp JW, Raybould HE (2006) Ligand-induced 5-HT3 receptor internalization in enteric neurons in rat ileum. Gastroenterology 131:97-107

Gallassi R, Di Sarro R, Morreale A, Amore M (2006) Memory impairment in patients with late-onset major depression: the effect of antidepressant therapy. J Affect Disord 91:243-250

Gandal MJ, Ehrlichman RS, Rudnick ND, Siegel SJ (2008) A novel electrophysiological model of chemotherapy-induced cognitive impairments in mice. Neuroscience 157:95-104

Genestier L, Paillot R, Quemeneur L, Izeradjene K, Revillard J-P (2000) Mechanisms of action of methotrexate. Immunopharmacology 47:247-257

Han R, Yang YM, Dietrich J, Luebke A, Mayer-Proschel M, Noble M (2008) Systemic 5-fluorouracil treatment causes a syndrome of delayed myelin destruction in the central nervous system. J Biol $7: 12$

Hede K (2008) Chemobrain is real but may need new name. J Natl Cancer Inst 100:162-169

Hitoshi S, Maruta N, Higashi M, Kumar A, Kato N, Ikenaka K (2007) Antidepressant drugs reverse the loss of adult neural stem cells following chronic stress. J Neurosci Res 85:3574-3585

Horsfield S, Rosse R, Tomasino V, Schwartz B, Mastropaolo J, Deutsch S (2002) Fluoxetine's effects on cognitive performance in patients with traumatic brain injury. Int J Psychiatry Med 32:337-344

Huang G-J, Herbert J (2006) Stimulation of neurogenesis in the hippocampus of the adult rat by fluoxetine requires rhythmic change in corticosterone. Biol Psychiatry 59:619-624

Huang GJ, Bannerman D, Flint J (2008) Chronic fluoxetine treatment alters behavior, but not adult hippocampal neurogenesis, in BALB/cJ mice. Mol Psychiatry 13:119-121

Imayoshi I, Sakamoto M, Ohtsuka T, Takao K, Miyakawa T, Yamaguchi M, Mori K, Ikeda T, Itohara S, Kageyama R (2008) Roles of continuous neurogenesis in the structural and functional integrity of the adult forebrain. Nat Neurosci 11:1153-1161 
Inagaki M, Yoshikawa E, Matsuoka Y, Sugawara Y, Nakano T, Akechi T, Wada N, Imoto S, Murakami K, Uchitomi Y (2007) Smaller regional volumes of brain gray and white matter demonstrated in breast cancer survivors exposed to adjuvant chemotherapy. Cancer 109:146-156

Jansen C, Miaskowski C, Dodd M, Dowling G, Kramer J (2005) Potential mechanisms for chemotherapy-induced impairments in cognitive function. Oncol Nurs Forum 32:1151-1163

Jin Y, Lim CM, Kim SW, Park JY, Seo JS, Han PL, Yoon SH, Lee JK (2009) Fluoxetine attenuates kainic acid-induced neuronal cell death in the mouse hippocampus. Brain Res 1281:108-116

Kaasa S, Olsnes BT, Mastekaasa A (1988) Neuropsychological evaluation of patients with inoperable non-small cell lung cancer treated with combination chemotherapy or radiotherapy. Acta Oncol 27:241-246

Kee N, Teixeira CM, Wang AH, Frankland PW (2007) Preferential incorporation of adult-generated granule cells into spatial memory networks in the dentate gyrus. Nat Neurosci 10:355-362

King MV, Sleight AJ, Woolley ML, Topham IA, Marsden CA, Fone KCF (2004) 5-HT6 receptor antagonists reverse delay-dependent deficits in novel object discrimination by enhancing consolidation-an effect sensitive to NMDA receptor antagonism. Neuropharmacology 47:195-204

Kitabatake Y, Sailor KA, G-1 M, Song H (2007) Adult neurogenesis and hippocampal memory function: new cells, more plasticity, new memories? Neurosurg Clin N Am 18:105-113

Kodama M, Fujioka T, Duman RS (2004) Chronic olanzapine or fluoxetine administration increases cell proliferation in hippocampus and prefrontal cortex of adult rat. Biol Psychiatry 56:570-580

Konat G, Kraszpulski M, James I, Zhang H-T, Abraham J (2008) Cognitive dysfunction induced by chronic administration of common cancer chemotherapeutics in rats. Metab Brain Dis 23:325-333

Lalonde R, Joyal CC, Botez MI (1993) Effects of folic acid and folinic acid on cognitive and motor behaviors in 20-month-old rats. Pharmacol Biochem Behav 44:703-707

Lassman A, Abrey L, Shah G, Panageas K, Begemann M, Malkin M, Raizer J (2006) Systemic high-dose intravenous methotrexate for central nervous system metastases. J Neuro-Oncol 78:255-260

Lee I, Hunsaker MR, Kesner RP (2005) The role of hippocampal subregions in detecting spatial novelty. Behav Neurosci 119:145-153

Lee GD, Longo DL, Wang Y, Rifkind JM, Abdul-Raman L, Mamczarz JA, Duffy KB, Spangler EL, Taub DD, Mattson MP, Ingram DK (2006) Transient improvement in cognitive function and synaptic plasticity in rats following cancer chemotherapy. Clin Cancer Res 12:198-205

Levkovitz Y, Caftori R, Avital A, Richter-Levin G (2002) The SSRIs drug fluoxetine, but not the noradrenergic tricyclic drug desipramine, improves memory performance during acute major depression. Brain Res Bull 58:345-350

Lledo PM, Alonso M, Grubb MS (2006) Adult neurogenesis and functional plasticity in neuronal circuits. Nat Rev Neurosci 7:179-193

Lobo E, Balthasar J (2002) Pharmacodynamic modeling of chemotherapeutic effects: application of a transit compartment model to characterize methotrexate effects in vitro. AAPS J 4:212-222

MacLeod JE, DeLeo JA, Hickey WF, Ahles TA, Saykin AJ, Bucci DJ (2007) Cancer chemotherapy impairs contextual but not cuespecific fear memory. Behav Brain Res 181:168-172

Marcussen AB, Flagstad P, Kristjansen PEG, Johansen FF, Englund U (2008) Increase in neurogenesis and behavioural benefit after chronic fluoxetine treatment in Wistar rats. Acta Neurol Scand 117:94-100
Matsuda T, Takayama T, Tashiro M, Nakamura Y, Ohashi Y, Shimozuma K (2005) Mild cognitive impairment after adjuvant chemotherapy in breast cancer patients-evaluation of appropriate research design and methodology to measure symptoms. Breast Cancer 12:279-287

Mayhew TM, Burton GJ (1988) Methodological problems in placental morphometry: apologia for the use of stereology based on sound sampling practice. Placenta 9:565-581

Monleon S, Vinader-Caerols C, Arenas MC, Parra A (2007) Antidepressant drugs and memory: insights from animal studies. Eur Neuropsychopharmacol 4:235-248

Mowla AMD, Mosavinasab MMD, Pani A (2007) Does fluoxetine have any effect on the cognition of patients with mild cognitive impairment? A double-blind, placebo-controlled, clinical trial. J Clin Psychopharmacol 27:67-70

Mumby DG, Gaskin S, Glenn MJ, Schramek TE, Lehmann H (2002) Hippocampal damage and exploratory preferences in rats: memory for objects, places, and contexts. Learn Mem 9:49-57

Mustafa S, Walker A, Bennett G, Wigmore P (2008) 5-Fluorouracil chemotherapy affects spatial working memory and newborn neurones in the adult rat hippocampus. Eur J Neurosci 10:1460-9568

Myers J (2009) Chemotherapy-related cognitive impairment. Clin J Oncol Nurs 13:413-421

Nakano T, Wenner M, Inagaki M, Kugaya A, Akechi T, Matsuoka Y, Sugahara Y, Imoto S, Murakami K, Uchitomi Y (2002) Relationship between distressing cancer-related recollections and hippocampal volume in cancer survivors. Am J Psychiatry 159:2087-2093

Peters G, Schornagel J, Milano G (1993) Clinical pharmacokinetics of anti-metabolites. Cancer Surv 17:123-156

Rousseau A, Marquet P, Debord J, Sabot C, Lachâtre G (2000) Adaptive control methods for the dose individualisation of anticancer agents. Clin Pharmacokinet 38:315-353

Saykin AJ, Ahles TA, McDonald BC (2003) Mechanisms of chemotherapy-induced cognitive disorders: neuropsychological, pathophysiological, and neuroimaging perspectives. Semin Clin Neuropsychiatry 8:201-216

Seigers R, Schagen SB, Beerling W, Boogerd W, van Tellingen O, van Dam FS, Koolhaas JM, Buwalda B (2007) Long-lasting suppression of hippocampal cell proliferation and impaired cognitive performance by methotrexate in the rat. Behav Brain Res 186:168-175

Seigers R, Schagen SB, Coppens CM, van der Most PJ, van Dam FSAM, Koolhaas JM, Buwalda B (2009) Methotrexate decreases hippocampal cell proliferation and induces memory deficits in rats. Behav Brain Res 201:279-284

Snyder JS, Choe JS, Clifford MA, Jeurling SI, Hurley P, Brown A, Kamhi JF, Cameron HA (2009) Adult-born hippocampal neurons are more numerous, faster maturing, and more involved in behavior in rats than in mice. J Neurosci 29:14484-14495

Stemmer SM, Stears JC, Burton BS, Jones RB, Simon JH (1994) White matter changes in patients with breast cancer treated with high-dose chemotherapy and autologous bone marrow support. Am J Neuroradiol 15:1267-1273

Stewart A, Bielajew C, Collins B, Parkinson M, Tomiak E (2006) A meta-analysis of the neuropsychological effects of adjuvant chemotherapy treatment in women treated for breast cancer. Clin Neuropsychol 20:76-89

Taillibert S, Voillery D, Bernard-Marty C (2007) Chemobrain: is systemic chemotherapy neurotoxic? Curr Opin Oncol 19:623627

Vermetten E, Vythilingam M, Southwick SM, Charney DS, Bremner JD (2003) Long-term treatment with paroxetine increases verbal declarative memory and hippocampal volume in posttraumatic stress disorder. Biol Psychiatry 54:693-702 
Vythilingam M, Vermetten E, Anderson GM, Luckenbaugh D, Anderson ER, Snow J, Staib LH, Charney DS, Bremner JD (2004) Hippocampal volume, memory, and cortisol status in major depressive disorder: effects of treatment. Biol Psychiatry $56: 101-112$

Wieneke MH, Dienst ER (1995) Neuropsychological assessment of cognitive functioning following chemotherapy for breast cancer. Psycho-oncol 4:61-66

Winocur G, Vardy J, Binns MA, Kerr L, Tannock I (2006) The effects of the anti-cancer drugs, methotrexate and 5- fluorouracil, on cognitive function in mice. Pharmacol Biochem Behav 85:66-75

Yang M, Kim J-S, Song M-S, Kim S-H, Kang SS, Bae C-S, Kim JC, Wang H, Shin T, Moon C (2010) Cyclophosphamide impairs hippocampus-dependent learning and memory in adult mice: possible involvement of hippocampal neurogenesis in chemotherapy-induced memory deficits. Neurobiol Learn Mem 93:487-494

Zhao C, Deng W, Gage FH (2008) Mechanisms and functional implications of adult neurogenesis. Cell 132:645-660 